\title{
Nederlandse Keel-Neus-Oorheelkundige Vereniging
}

$106^{\mathrm{e}}$ Vergadering te Leiden, 26 en 27 november 1960

Dutch Oto-Rhino-Laryngological Society

106th Meeting, Leyden, 27th and 28th November, 1960

President: H. Navis Secretary: W. H. Struben

M. P. Lansberg: Latent Idiopathic Nystagmus (report not received)

P. Voorhorst: Housedust Allergy (report not received)

G. A. Hoogland: Papilloma epiglottidis (report not received)

P. H. Damsté: Incomplete Mutations as a Cause of Voice

Troubles in Adults 118

1. A. Bos: About Neuralgia and Snoring (report not reveived)

J. Kuilman: 1. Cancer of the Auditory Canal . . . 119

2. Thorotrast Granuloma of the Pharynx with

Left Total Recurrent Paralysis, 18 Years

after Angiography

121

A. H. Bogaars: Survey of 100 Cases of Corpora Aliena in the Oesophagus 125

E. H. Huizing: Report on Malignant Tumours of the Nose, Paranasal Sinuses and Nasopharynx, with a Discussion of 2 Neurogenic Tumours, 3 Plasmocytomas and 2 Nasopharyngeal Chordomas 127

Pract. Oto-Rhino-Laryngologica, Vol. 24, Nr. 2. (1962) 9* 